\title{
Article \\ Discrete Coating of CNT on Carbon Fiber Surfaces and the Effect on Improving the Electrochemical Performance of VRFB Systems
}

\author{
Zhongxu Tai ${ }^{1} \mathbb{D}$, Dongying Ju ${ }^{1,2,3, *}$, Susumu Sato ${ }^{1}$ and Kenzo Hanawa ${ }^{3}$ \\ 1 Department of Information System, Saitama Institute of Technology, Fukaya 3690293, Japan; \\ i9004jye@sit.ac.jp (Z.T.); ssato@sit.ac.jp (S.S.) \\ 2 Ningbo Haizhi Institute of Material Industry Innovation, Ningbo 315000, China \\ 3 Tokyo Green Power Electric Research Institute Co., Ltd., Tokyo 111022, Japan; hanawa@gpower.jp \\ * Correspondence: dyju@sit.ac.jp; Tel.: +81-048-585-6902
}

Citation: Tai, Z.; Ju, D.; Sato, S.;

Hanawa, K. Discrete Coating of CNT on Carbon Fiber Surfaces and the Effect on Improving the Electrochemical Performance of VRFB Systems. Coatings 2021, 11, 736 . https://doi.org/10.3390/ coatings11060736

Academic Editor: Dimitrios Tasis

Received: 6 May 2021

Accepted: 16 June 2021

Published: 18 June 2021

Publisher's Note: MDPI stays neutral with regard to jurisdictional claims in published maps and institutional affiliations.

Copyright: (c) 2021 by the authors. Licensee MDPI, Basel, Switzerland. This article is an open access article distributed under the terms and conditions of the Creative Commons Attribution (CC BY) license (https:// creativecommons.org/licenses/by/ $4.0 /)$.

\begin{abstract}
Carbon fiber, as an electrode material, has been widely used in all-vanadium liquid flow batteries. In order to further reduce the size of the all-vanadium storage system, it is imperative to increase the current density of the battery and to achieve high conductivity and large electrostatic capacitance. The graphitization of the electrode material and the improvement in the specific surface area of the electrode surface also greatly affect the performance of all-vanadium redox liquid flow batteries. Therefore, in this paper, carbon nanotubes (CNTs) with a small diameter and a large specific surface area were coated on the electrode surface of the VRFB system by the dispersion method to improve the cell performance. The performance of the surface-modified electrode was also verified by Raman spectroscopy, XRD and SEM surface observations and charge/discharge experiments.
\end{abstract}

Keywords: VRFB; energy storage; carbon fiber

\section{Introduction}

The liquid flow battery is an electrochemical energy storage technology proposed by Thaller (NASA Lewis Research Center, Cleveland, OH, USA) in 1974 [1,2]. The liquid flow battery is also known as a battery active material renewable fuel cell [3]. When vanadium ions are used as the active material in the battery, called a vanadium liquid flow battery (VRFB), the vanadium electrolyte in the liquid storage tank is pressed into the battery stack through an external pump during system operation to complete the electrochemical reaction. $\mathrm{V}^{4+}$ in the positive electrode is oxidized to $\mathrm{V}^{5+}$ during charging, and $\mathrm{V}^{3+}$ in the negative electrode is reduced to $\mathrm{V}^{2+}$. The reverse reaction occurs during the discharge process. The reaction is as follows.

Positive electrode reaction:

$$
\mathrm{VO}^{2+}+\mathrm{H}_{2} \mathrm{O} \underset{\text { discharge }}{\stackrel{\text { charge }}{\rightleftarrows}} \mathrm{VO}_{2}^{+}+\mathrm{e}^{-}+2 \mathrm{H}^{+} \quad \text { at } \mathrm{E}^{0}=+1.0 \mathrm{~V}
$$

Negative electrode reaction:

$$
\mathrm{V}^{3+}+\mathrm{e}^{-} \underset{\text { discharge }}{\stackrel{\text { charge }}{\rightleftarrows}} \mathrm{V}^{2+} \text { at } \mathrm{E}^{0}=-0.26 \mathrm{~V}
$$

As an energy storage battery, the all-vanadium liquid flow battery has been widely used in various energy storage fields, including large power stations, photovoltaic power generation and wind power generation [4-7]. However, the disadvantages of a low energy density and a large size need to be further addressed [8-10]. Therefore, reducing the size of all-vanadium liquid flow batteries and increasing the energy density and current density of 
the batteries are the main objectives of current research and development [11-13]. This goal is achieved mainly through two ways: one is to improve the performance of the battery component materials, and the other is to optimize the design of the battery frame and flow path $[14,15]$. One of them is about the battery component materials, which mainly include the electrode materials and diaphragm materials of the battery. Electrode materials are improved mainly by means of heat treatment and surface modification [16-20]. The heat treatment process can improve the carbonization of the electrode to reduce the resistance of the electrode [21,22]. However, while improving the carbonization, we believe that for aqueous solution batteries, the hydrophilicity of the electrode should be improved at the same time, and excessive heat treatment will reduce the hydrophilicity of the electrode [23], thus reducing the charge and discharge performance. Surface modification of the electrode is mainly conducted by increasing the specific surface area of the carbon ballast [24-26], which increases the contact area between the carbon ballast and the electrolyte, thus improving the reaction rate and reducing the charge mobility resistance [27-30].

As a key component of the VFRB, the electrode not only provides the site for the redox reaction of vanadium ions but also plays an important role in the performance of the battery. The performance of the electrode directly affects the charging and discharging performance of the VFRB. Carbon felt is a widely used electrode material due to its good stability, high conductivity and low cost. However, carbon felt electrodes also have some disadvantages, such as poor electrochemical activity and a small specific surface area. These problems need to be solved by surface modification. In 2016, Venkata Yarlagadda et al. published a paper $[31,32]$ showing studies which increased the specific surface area of the electrode to 29 times the original one by producing multi-walled carbon nanotubes directly on the electrode surface by the electrical deposition method. The efficiency of the $\mathrm{H}_{2}-\mathrm{Br}_{2}$ fuel cell was $16 \%$ higher than that using a triple-layer fuel cell at an $80 \%$ discharge voltage. In 2019, H.R. Jiang et al. published a paper [33,34] in which a two-hole graphite felt electrode was prepared by a simple and effective catalytic etching method with seven times the specific surface area of the original stone carbon felt, current densities of 300 and $400 \mathrm{~mA} / \mathrm{cm}^{2}$ and energy efficiencies of $82.47 \%$ and $77.69 \%$. The performance of the carbon felt electrode was effectively improved.

In order to further improve the performance of carbon electrodes in VRFB systems, in this paper, a method is proposed to dispersively coat carbon nanotubes (CNTs) with small diameters and large specific surface areas on the surface of carbon electrode fibers in VRFB systems. Furthermore, the carbon electrodes were heat-treated at various temperature conditions, and the optimum heat treatment conditions were found to improve the electrode performance. The performance of the surface-modified electrodes was verified by Raman spectrum, XRD and SEM surface observations and charge/discharge experiments, which also proved that the method proposed in this thesis is effective.

\section{Experimental Methods}

In this study, the dispersion of multi-walled carbon nanotubes was treated with different dispersions and the dispersions were analyzed using a ZC-3000 ZETA potentiostat from Kyowa Interface Science Co., Ltd. (Niiza, Japan). To ensure the uniformity of the coating, we applied the dispersed CNT solution in batches on both the front and back sides of the electrodes, which were heated and dried. The VRFB used for charge/discharge experiments was a homemade spiral pump-driven cell with an electrode area of $5 \times 10 \mathrm{~cm}$. For the data of the charge/discharge experiments, SEM-EDS(JEOL Ltd. JSM-5510 Tokyo, Japan) observation analysis, Raman spectroscopy analysis(JASCO Corporation. NRS4100, Tokyo, Japan) and XRD (Rigaku Corporation, RINT2500HF, Tokyo, Japan) surface crystallography analysis were performed on the electrode surface. The obtained analytical data were calculated, and the calculated results were compared in order to summarize the experimental results. 


\subsection{Experimental Conditions}

The CNTs used in this experiment were multi-walled carbon nanotubes produced by Wako Pure Chemical Industries, Ltd (Tokyo, Japan), commercially available multi-walled CNTs with an average diameter of $10 \mathrm{~nm}$ and an average length of $1 \mu \mathrm{m}$. The dispersion medium mainly contained deionized water and ethanol solution, and the surfactant was SDBS (sodium dodecylbenzene sulfonate). Here, $0.006 \mathrm{~g}$ of CNTs was placed in three different solvents, stirred for $15 \mathrm{~min}$, sonicated for $20 \mathrm{~min}$ and left for $1 \mathrm{~h}$. The stability of the dispersed solution was determined by measuring the ZETA potential. The ultrasonic treatment instrument was model W-113A manufactured by Honda Electronics, Ltd. (Tokyo, Japan) and the ultrasonic treatment conditions were $60^{\circ} \mathrm{C}, 45 \mathrm{KHZ}$ and $20 \mathrm{~min}$, as shown in Figure 1.

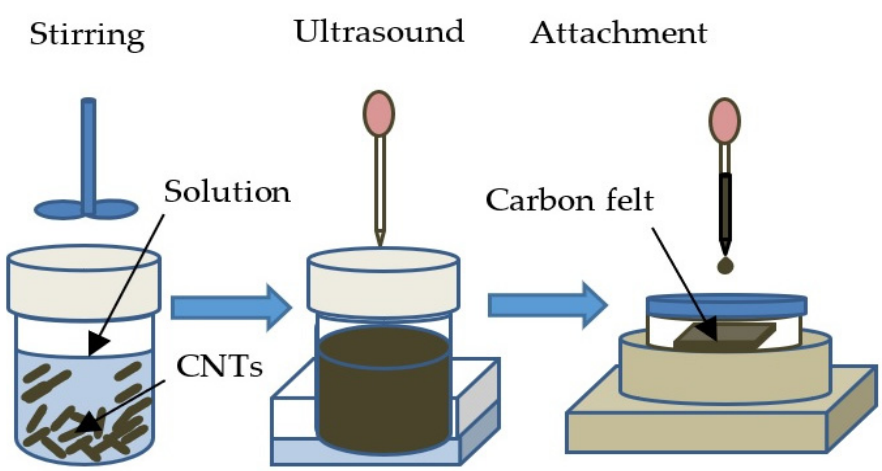

Figure 1. CNT dispersion and carbon fiber modification.

\subsection{Calculation Method}

The charge/discharge experiment was performed with a constant current charge/ discharge, an electrolyte flow rate of $2.4 \mathrm{~mL} \mathrm{~min}^{-1} \mathrm{~cm}^{-2}$ and a carbon felt compression ratio of $30 \%$. The charge/discharge experiments were carried out on untreated carbon felt and treated carbon felt, and the charge/discharge data results were calculated to compare the experimental results. The charge and discharge internal resistance $\left(I_{R}\right)$, voltage efficiency $\left(E_{V}\right)$, coulombic efficiency $\left(E_{C}\right)$, energy efficiency $\left(E_{E}\right)$, energy density $\left(E_{D}\right)$ and output density $\left(O_{D}\right)$ of the battery were calculated based on the constant current charge and discharge curves. The calculation equations are shown in Equations (3)-(8).

$$
\begin{gathered}
I_{R}=\frac{U_{\text {avg.charge }}-U_{\text {avg.discharge }}}{2 C_{D}} \\
E_{V}=\frac{U_{\text {avg.discharge }}}{U_{\text {avg.charge }}} \times 100 \% \\
E_{C}=\frac{\int i_{\text {discharge }}(t) d t}{\int i_{\text {charge }}(t) d t} \times 100 \% \\
E_{E}=E_{V} \times E_{C} \\
O_{D}(\mathrm{~W} / \mathrm{L})=\frac{I \times U_{\text {avg.discharge }}}{V_{1}} \\
E_{D}(\mathrm{Wh} / \mathrm{L})=\frac{I \times T_{d} \times U_{\text {avg.discharge }}}{V_{1}}
\end{gathered}
$$




\section{Experimental Results}

3.1. Dispersion Experiments of CNTs and SEM-EDS Surface Observation and Elemental Analysis

The dispersions of the three dispersions at different concentrations were compared by measuring the ZETA potential. The results show that the $80 \%$ ethanol solution (a), $0.1 \mathrm{~mol} / \mathrm{L}$ SDBS ethanol solution (b) had the best dispersion. The dispersion potential is negative and arranged in a gradient. The measurement results are shown in Figure 2. Since the SDBS ethanol solution produced a large number of bubbles after sonication, the solution started to solidify after $2 \mathrm{~h}$ of standing, and the precipitation was obvious after $6 \mathrm{~h}$ of standing. Therefore, the $80 \%$ ethanol solution was used in this experiment.

The $100 \mathrm{~mL}$ of dispersed solution was heated and dried after being dropped into the carbon felt electrode several times. The surface state and elements of the carbon fiber electrodes were observed and analyzed by SEM-EDS. The SEM images of the untreated electrode, Figure 3(a1-a3), and the treated electrode, Figure 3(b1-b3), are shown in Figure 3. The SEM comparison shows that the dispersed CNTs completely adhered to the surface of the carbon felt fibers.

The results of the EDS elemental analysis are shown in Table 1 and Figure 4 . It can be seen from the elemental analysis results that the carbon element percentage of the treated carbon felt increased by $4.25 \%$.

Table 1. EDS Surface Element Analysis Results Comparison.

\begin{tabular}{cccc}
\hline & C Ka (\%) & O Ka (\%) & O/C \\
\hline$($ a) & 87.23 & 12.77 & 0.14 \\
$(\mathbf{b})$ & 91.48 & 8.52 & 0.09 \\
\hline
\end{tabular}



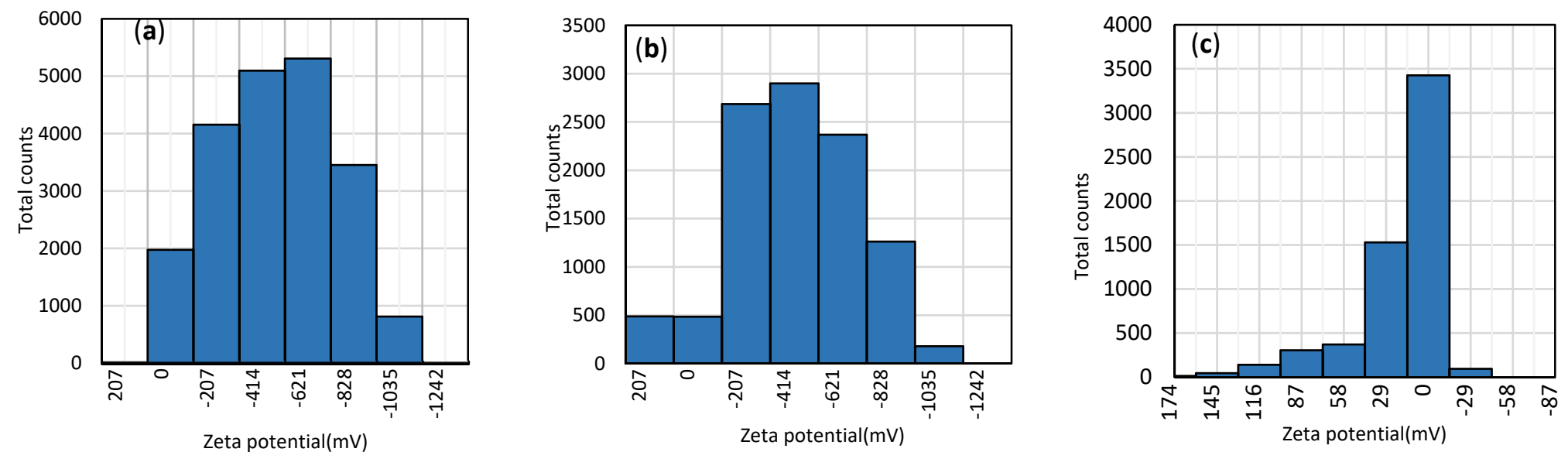

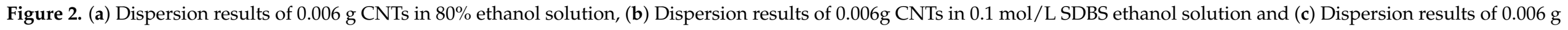
CNTs in $2 \%$ SDBS aqueous solution.

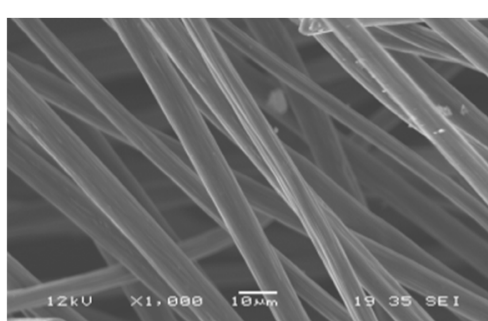

(a1)

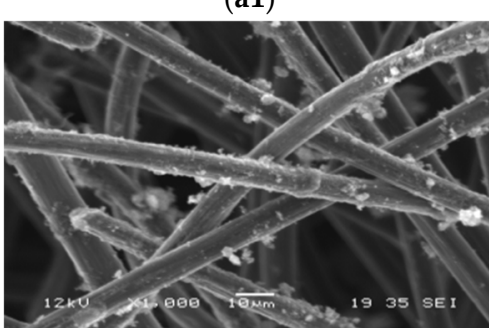

(b1)

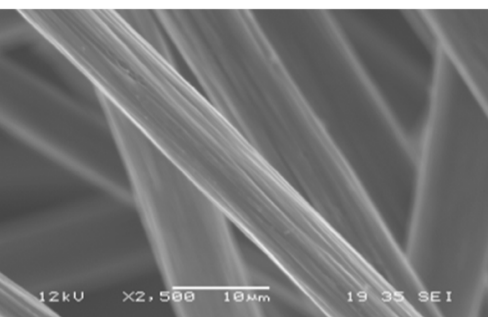

(a2)

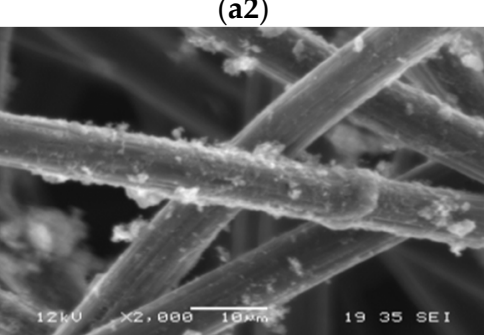

(b2)

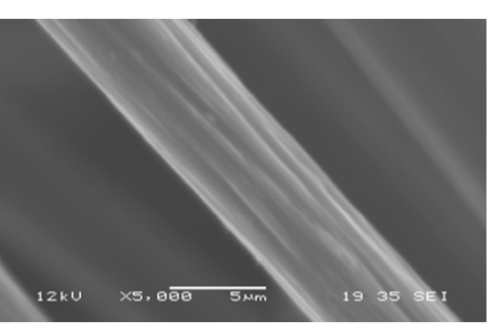

(a3)

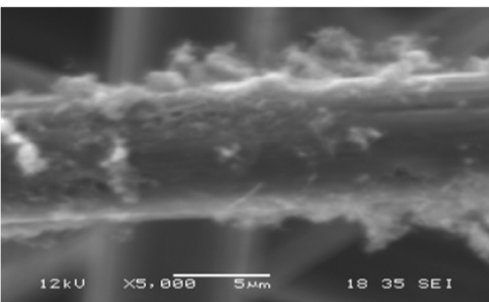

(b3)

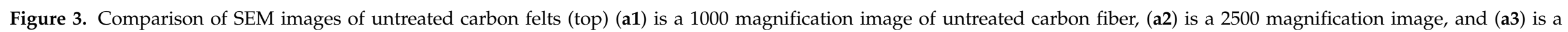

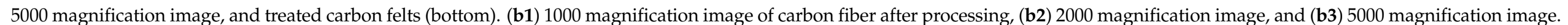



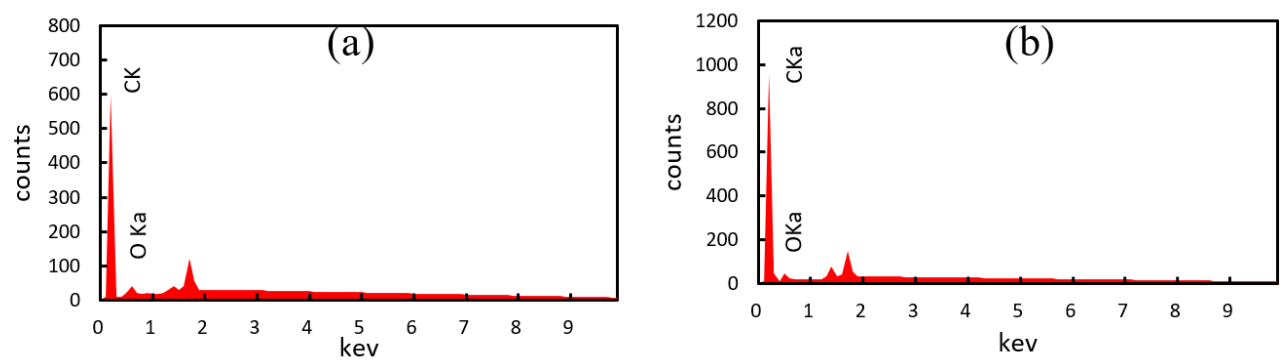

Figure 4. EDS surface elemental analysis results for (a) untreated carbon felt and (b) carbon felt after attachment treatment.

\subsection{Charge and Discharge Experiments and Impedance Measurement Evaluation}

The experimental results are shown in Figure 5 ((a) untreated carbon felt, (b) treated carbon felt) after conducting a constant current charge/discharge experiment on a single cell with a current density of $100-500 \mathrm{~mA} / \mathrm{cm}^{2}$. The maximum power density of the untreated carbon felt electrode is $300 \mathrm{~mA} / \mathrm{cm}^{2}$, and the charging voltage is $1.8 \mathrm{~V}$. The treated carbon felt electrode can reach $400 \mathrm{~mA} / \mathrm{cm}^{2}$, and the charging voltage is $1.6-1.7 \mathrm{~V}$. The charging and discharging data were calculated according to Equations (3)-(8), as shown in Table 2. It can be seen from Table 2 that the $I_{R}$ of the treated carbon felt is two times lower than that of the treated carbon felt, and the $E_{V}$ and $E_{E}$ are increased by about $15 \%$. This is because the surface coating of the carbon felt with CNTs improves the conductivity of the electrode and increases the specific surface area, thus reducing the charge/discharge internal resistance.
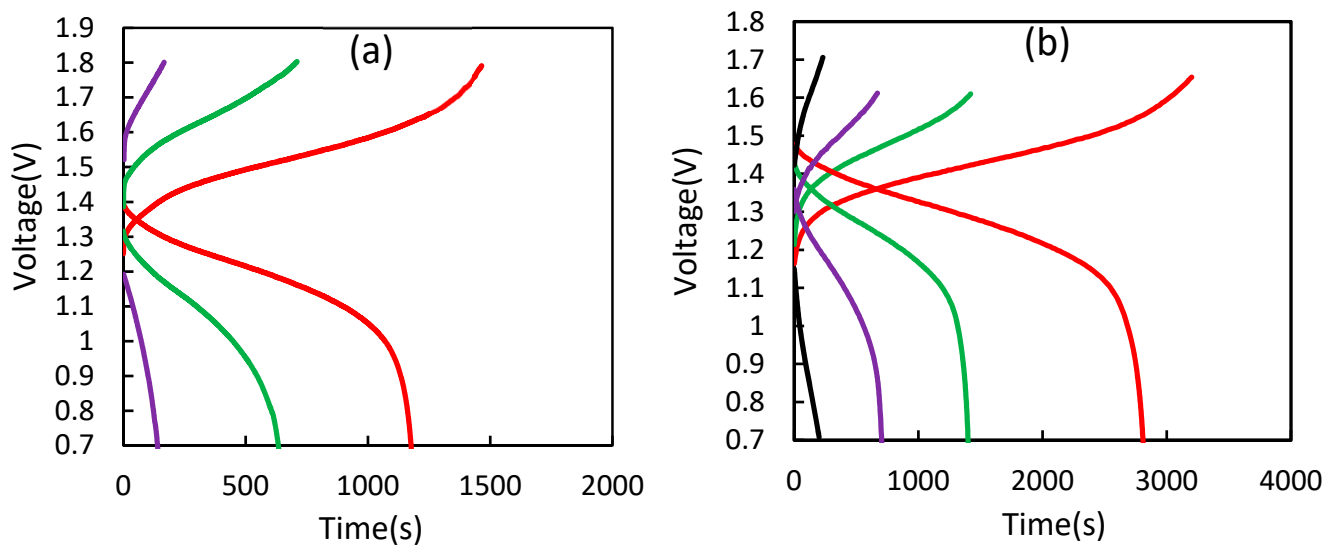

$-100 \mathrm{~mA} / \mathrm{cm}^{2}-200 \mathrm{~mA} / \mathrm{cm}^{2}-300 \mathrm{~mA} / \mathrm{cm}^{2}-400 \mathrm{~mA} / \mathrm{cm}^{2}$

Figure 5. Charge and discharge data. (a) Constant-current charge/discharge experiment for untreated electrode. (b) Constant-current charge/discharge experiment of treated electrode.

Table 2. Constant Current Charge and Discharge Data (A: Untreated Carbon Felt; B: Treated Carbon Felt).

\begin{tabular}{ccccccccc}
\hline & \multicolumn{2}{c}{$\mathbf{1 0 0} \mathbf{~} \mathbf{A} / \mathbf{c m}^{\mathbf{2}}$} & \multicolumn{2}{c}{$\mathbf{2 0 0} \mathbf{~} \mathbf{A} / \mathbf{c m}^{\mathbf{2}}$} & \multicolumn{2}{c}{$\mathbf{3 0 0} \mathbf{~} \mathbf{A} / \mathbf{c m}^{\mathbf{2}}$} & \multicolumn{2}{c}{$\mathbf{4 0 0} \mathbf{~} \mathbf{A} / \mathbf{c m}^{\mathbf{2}}$} \\
\cline { 2 - 9 } & $\mathbf{A}$ & $\mathbf{B}$ & $\mathbf{A}$ & $\mathbf{B}$ & $\mathbf{A}$ & $\mathbf{B}$ & $\mathbf{A}$ & $\mathbf{B}$ \\
\hline$I_{R}(\Omega)$ & 1.715 & 0.65 & 1.34 & 0.56 & 1.25 & 0.61 & - & 0.68 \\
$E_{V}(\%)$ & 77.63 & 90.95 & 66.02 & 84.72 & 58.03 & 82.61 & - & 75.35 \\
$E_{C}(\%)$ & 82.73 & 88.13 & 96.47 & 92.50 & 92.17 & 82.61 & - & 88.31 \\
$O_{D}(\mathrm{~W} / \mathrm{L})$ & 297.5 & 326.5 & 270.5 & 314.75 & 246.5 & 23750 & - & 283.5 \\
$E_{D}(\mathrm{Wh} / \mathrm{L})$ & 100.16 & 255.76 & 49.29 & 129.40 & 10.48 & 1253.47 & - & 53.55 \\
$E_{E}(\%)$ & 64.22 & 80.15 & 63.69 & 78.37 & 53.49 & 68.24 & - & 66.54 \\
\hline
\end{tabular}


For the charge/discharge experimental data, the AC impedance of the battery was measured, and the results (Nyquist plot) are shown in Figure 6 for the test range of $10^{5} \rightarrow 0.1 \mathrm{~Hz}$. The intersection of the starting position of the curve with the $\mathrm{x}$-axis is the on-state resistance $\left(R_{L}\right)$ of the battery itself. In the figure, the half-circle part is the charge movement resistance $\left(R_{P}\right)$ in the high-frequency region, and the diagonal part is the material movement resistance $\left(R_{D}\right)$ in the low-frequency region. $\sigma$ is the Warburg coefficient, $\omega$ is the frequency and $C_{d}$ is the double-layer capacitance. The calculation equation is shown in (9) and (10).

$$
\begin{aligned}
& Z^{\prime}=R_{L}+\frac{\frac{\sigma}{\sqrt{\omega}}+R_{P}}{\left(1+\sigma \sqrt{\omega} C_{d}\right)^{2}+\omega^{2} C_{d}^{2}\left(\frac{\sigma}{\sqrt{\omega}}+R_{P}\right)^{2}} \\
& Z^{\prime \prime}=\frac{\frac{\sigma}{\sqrt{\omega}}\left(1+\sigma \sqrt{\omega} C_{d}\right)^{2}+\omega C_{d}\left(\frac{\sigma}{\sqrt{\omega}}+R_{P}\right)^{2}}{\left(1+\sigma \sqrt{\omega} C_{d}\right)^{2}+\omega^{2} C_{d}^{2}\left(\frac{\sigma}{\sqrt{\omega}}+R_{P}\right)^{2}}
\end{aligned}
$$

The main purpose of this experiment is to review the charge movement resistance $R_{P}$ in the high-frequency region and the matter movement resistance $R_{D}$ in the low-frequency region. From the measured Nyquist diagram, it can be calculated that $R_{P}=0.7 \Omega$ and $R_{D}=1 \Omega$ for the untreated carbon felt and $R_{P}=0.025 \Omega$ and $R_{D}=0.035 \Omega$ for the treated carbon felt. It can be seen that the charge and discharge impedance of the coated carbon felt is reduced by about five times.
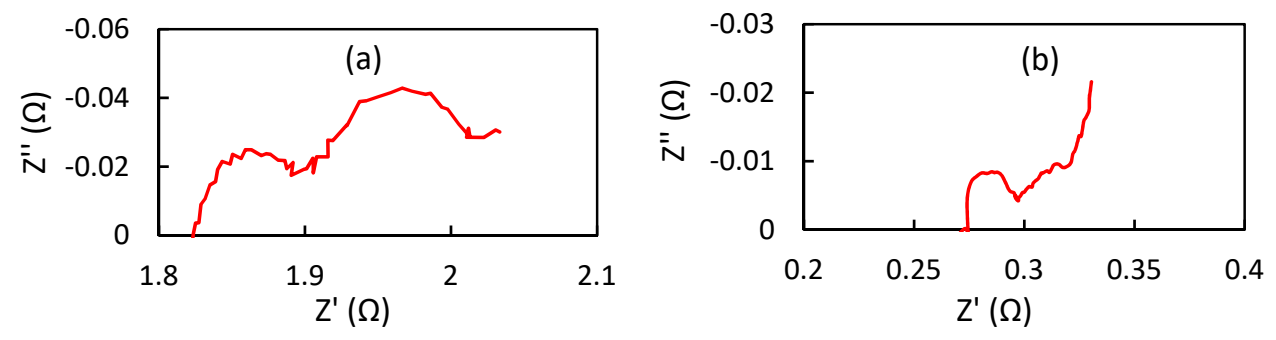

Figure 6. Single battery cell Nyquist figure. (a) AC impedance results of untreated electrode, (b) AC impedance results of the treated electrode.

\subsection{Raman Spectroscopic Detection and XRD Surface Crystallization Analysis}

For the results of constant current charging and discharging, we performed Raman spectroscopy and XRD surface crystallographic analysis on two carbon felts.

In this paper, we use the common method of Raman spectroscopy to analyze carbon materials. There are two characteristic peaks in the Raman spectrum of carbon materials: the $G$ peak near $1580 \mathrm{~cm}^{-1}$ and the D peak near $1360 \mathrm{~cm}^{-1}$ [35]. Researchers usually go through the $\mathrm{D}$ and $\mathrm{G}$ peaks. The integrated area ratio $I_{D} / I_{G}$ is used to determine the integrity of the carbon material. The larger the $I_{D} / I_{G}$ ratio, the lower the structural integrity of the carbon material. The smaller the $I_{D} / I_{G}$ ratio, the higher the structural integrity of the carbon material $[36,37]$. In this study, the treated carbon fiber electrodes were tested by Raman spectroscopy using the NRS-4100 from JASCO (JASCO Corporation. Tokyo, Japan). The measured Raman spectra are shown in Figure 7, and the measured data are shown in Table 3. Combining the Raman spectra and the measured data, it can be seen that the peak shapes of the D and $G$ peaks of the coated treated carbon felt became relatively sharp and obvious, the integrated area ratio and half-height width of the peaks also became smaller, the characteristic peak $G^{\prime}$ appeared near $2700 \mathrm{~cm}^{-1}$ of the carbon felt and the ratio of $I_{D} / I_{G}$ decreased by 0.068 . 

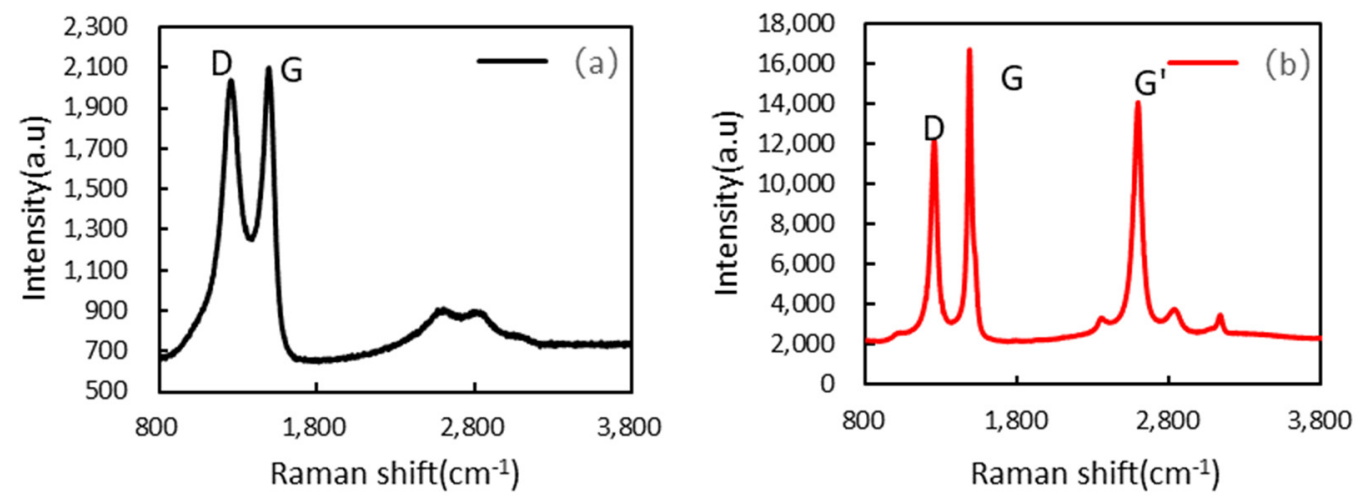

Figure 7. Structural analysis result by Raman spectroscopy. (a) Raman spectra of untreated electrode. (b) Raman spectra of treated electrodes.

Table 3. Calculated Results of Raman Analysis.

\begin{tabular}{|c|c|c|c|c|c|}
\hline \multirow[b]{2}{*}{ Sample } & \multicolumn{2}{|c|}{ D Peak } & \multicolumn{2}{|c|}{ G Peak } & \multirow{2}{*}{$\begin{array}{l}I_{D} / I_{G} \\
\text { (Area) }\end{array}$} \\
\hline & $\begin{array}{l}\text { Raman Shift } \\
\quad\left(\mathrm{cm}^{-1}\right)\end{array}$ & $\begin{array}{l}\text { FWHM } \\
\left(\mathrm{cm}^{-1}\right)\end{array}$ & $\begin{array}{l}\text { Raman Shift } \\
\left(\mathrm{cm}^{-1}\right)\end{array}$ & $\begin{array}{l}\text { FWHM } \\
\left(\mathrm{cm}^{-1}\right)\end{array}$ & \\
\hline a & 1252 & 307.33 & 1487 & 147.81 & 1.038 \\
\hline$b$ & 1255 & 71.90 & 1491 & 52.01 & 0.97 \\
\hline
\end{tabular}

For the surface crystal structure, untreated and treated carbon fibers were analyzed using the RINT 2500 VHF from RIGAKU Corporation, Japan, under the following test conditions: voltage: $40 \mathrm{kV}: 30 \mathrm{~mA}(\mathrm{Cu})$. The measurement results are shown in Figure 8 . It can be seen that the shape of the (002) diffraction peak for $2 \theta=25^{\circ}$ is basically the same. However, the intensity of the peak increases after the coating treatment. There is no significant difference in the (100) diffraction peak at $2 \theta=43^{\circ}$.

$$
\begin{gathered}
d_{002}=\frac{\lambda}{2 \sin \theta} \\
L=\frac{K \lambda}{\beta \cos \theta}
\end{gathered}
$$
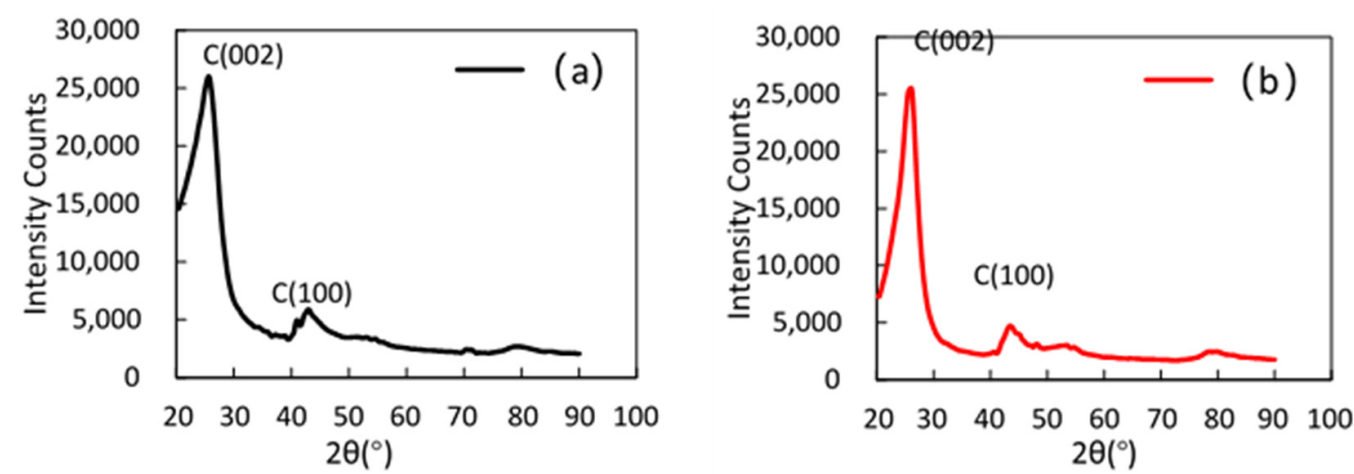

Figure 8. Results of crystal structure analysis by XRD: (a) unprocessed; (b) processed.

According to Equations (11) and (12), the layer spacing $d_{002}$ of the carbon fibber graphite crystallites and the thickness of the crystallite stack $L c$ can be calculated [38]. The (100) peak in the XRD spectrum can be used to calculate the direction of the graphite crystallite along the axis, the crystal plane width $L a$ and the diffraction angle of the $\theta$ crystal plane diffraction peak; $\lambda$ is the wavelength $(\lambda=0.1541 \mathrm{~nm}) ; K$ is the shape factor, $K=0.94$ 
when $L c$ is calculated, and $K=1.84$ when La is calculated; and $\beta$ is the measured full width at half maximum. The calculation results are shown in Table 4 .

Table 4. XRD Patterns of Untreated and Treated Carbon Felts (a: Untreated; b: Treated Carbon Felts).

\begin{tabular}{ccccccccc}
\hline \multirow{2}{*}{ CF } & \multicolumn{3}{c}{ C (002) Crystallographic Plane } & \multicolumn{3}{c}{ C (100) Crystallographic Plane } \\
\cline { 2 - 9 } & $\mathbf{2 \theta} /^{\circ}$ & $\boldsymbol{d} / \mathbf{n m}$ & $\beta / \mathbf{r a d}$ & $\boldsymbol{L c} / \mathbf{n m}$ & $\mathbf{2 \theta} /^{\circ}$ & $\boldsymbol{d} / \mathbf{n m}$ & $\beta / \mathbf{r a d}$ & $\boldsymbol{L a} / \mathbf{n m}$ \\
\hline a & 25.6 & 0.356 & 0.141 & 1.054 & 42.8 & 0.228 & 1.385 & 0.221 \\
$\mathrm{~b}$ & 25.8 & 0.354 & 0.100 & 1.488 & 43.4 & 0.224 & 1.237 & 0.246 \\
\hline
\end{tabular}

From the comparison of the calculated results in Table 4, it can be found that there is no significant difference between the crystal spacing $d_{002}$ and the crystal spacing $d_{100}$ of the untreated and treated electrodes; the radial size $L c$ and the axial size $L a$ of the crystals of the treated carbon fiber electrodes become larger. The larger crystallite size indicates a more complete development and a higher degree of graphitization [39]. Therefore, it was theoretically demonstrated that the performance of the treated carbon cellulose electrodes was higher than that of the untreated electrodes.

\section{Conclusions}

In this paper, we improved the VRFB system by proposing a method for dispersion coating of CNTs on the surface of carbon electrodes. The following results were obtained from this study.

1. The performance of the existing carbon felt is improved by the CNT surface coating method. Charge and discharge data show that the current density of VRFB can reach up to $400 \mathrm{~mA} / \mathrm{cm}^{2}$. At a current density of $200 \mathrm{~mA} / \mathrm{cm}^{2}$, the energy efficiency is close to $80 \%$, which is about $15 \%$ higher than that of the untreated carbon felt.

2. AC impedance data surfaced showing the treated carbon felt reduces the $R_{P}$ by $0.68 \Omega$ and the $R_{D}$ by $0.96 \Omega$ during charging and discharging, meaning that the charge and discharge internal resistance of VRFB is reduced by three times.

3. Raman and XRD analyses of the two carbon felts were performed, and the experimental results showed that the $I_{D} / I_{G}$ of the treated carbon felts decreased by 0.068 , while the XRD calculation data showed that the crystal radial size $L c$ and axial size $L a$ of the treated carbon fiber electrode became larger.

4. In this study, the performance of the coated treated carbon felts was tested, but the durability of the treated carbon felts needs further study.

Author Contributions: Data compilation, Z.T.; formal analysis, S.S., K.H. and Z.T.; funding access, D.J.; Surveys, Z.T. and K.H.; Methodology, Z.T. and D.J.; Project Management, D.J.; Software Z.T. Supervision, D.J.; Writing—original draft, Z.T.; Writing—review and editing, D.J. All authors have read and agreed to the published version of the manuscript.

Funding: This research was funded by the Ningbo Haizhi Institute of Material Industry Innovation, China.

Institutional Review Board Statement: Not applicable.

Informed Consent Statement: Not applicable.

Data Availability Statement: The data used to support the findings of this study are available from the corresponding author upon request.

Acknowledgments: This research is based on the support of the new multifunctional secondary battery energy storage project of the Ningbo Haizhi Material Industry Innovation Research Institute.

Conflicts of Interest: The authors declare no conflict of interest. The funders had no role in the design of the study; in the collection, analyses, or interpretation of data; in the writing of the manuscript, or in the decision to publish the results. 


\section{Nomenclature}

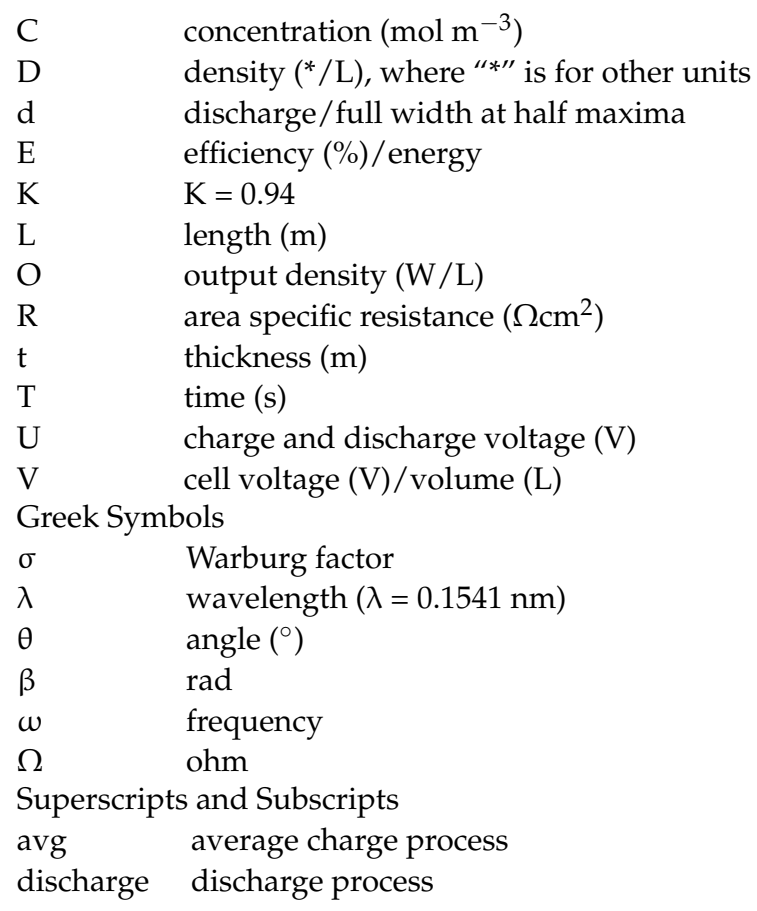

\section{References}

1. Thallerl, H.; Nice, A.W. Fluid battery prom ises economical storage. Power Eng. 1981, 85, 56-58.

2. Thaller, L.H. Electrically Rechargeable Redox Flow Cells. In Proceedings of the 9th Intersociety Energy Conversion Engineering Conference, San Francisco, CA, USA, 26-30 August 1974; American Society of Mechanical Engineers: New York, NY, USA, 1974; pp. 924-928.

3. Shunichi, U. Multipurpose redox flow battery. In Development Trend of Redox Flow Battery; CMC Publishing: Chattanooga, TN, USA, 2017; pp. 162-175.

4. Kear, G.; Shah, A.A.; Walsh, F.C. Development of the all-vanadium redox flow battery for energy storage: A review of technological, financial and policy aspects. Int. J. Energy Res. 2012, 36, 1105-1120. [CrossRef]

5. Holzman, D.C. The Vanadium Advantage: Flow Batteries Put Wind Energy in the Bank. Environ. Health Perspect. 2007, 115, A358-A361. [CrossRef]

6. Shigematsu, T. Redox Flow Battery for Energy Storage. SEI Tech. Rev. 2011, 73, 4-13.

7. Liu, X.; Li, K. Energy storage devices in electrified railway systems. Transp. Saf. Environ. 2020, 2, 183-201. [CrossRef]

8. Jiang, H.; Wei, L.; Fan, X.; Xu, J.; Shyy, W.; Zhao, T. A novel energy storage system incorporating electrically rechargeable liquid fuels as the storage medium. Sci. Bull. 2019, 64, 270-280. [CrossRef]

9. Ortiz-Martínez, V.M.; Gómez-Coma, L.; Perez, G.; Ortiz, A.; Ortiz, I. The roles of ionic liquids as new electrolytes in redox flow batteries. Sep. Purif. Technol. 2020, 252, 117436. [CrossRef]

10. Doetsch, C.; Pohlig, A. The Use of Flow Batteries in Storing Electricity for National Grids. In Future Energy-Improved: Sustainable and Clean Options for Our Planet, 3rd ed.; Elsevier: Amsterdam, The Netherlands, 2020; pp. 263-277.

11. Zhu, Z.; Meng, Y.; Wang, M.; Yin, Y.; Chen, W. A high-performance aqueous iron-hydrogen gas battery. Mater. Today Energy 2021, 19, 100603. [CrossRef]

12. Larcher, D.; Tarascon, J.M. Towards greener and more sustainable batteries for electrical energy storage. Nat. Chem. 2015, 7, 19-29. [CrossRef]

13. Gür, T.M. Review of electrical energy storage technologies, materials and systems: Challenges and prospects for large-scale grid storage. Energy Environ. Sci. 2018, 11, 2696-2767. [CrossRef]

14. Skyllas-Kazacos, M.; Rychcik, M.; Robins, R.G.; Fane, A.G.; Green, M.A. New all-vanadium redox flow cell. J. Electrochem. Soc. 1986, 133, 1057. [CrossRef]

15. Wu, Q.; Zhang, X.; Lv, Y.; Lin, L.; Liu, Y.; Zhou, X. Bio-inspired multiscale-pore-network structured carbon felt with enhanced mass transfer and activity for vanadium redox flow batteries. J. Mater. Chem. 2018, 6, 20347-20355. [CrossRef]

16. Wu, X.; Xu, H.; Shen, Y.; Xu, P.; Lu, L.; Fu, J.; Zhao, H. Treatment of graphite felt by modified Hummers method for the positive electrode of vanadium redox flow battery. Electrochim. Acta 2014, 138, 264-269. [CrossRef]

17. Jiang, H.R.; Shyy, W.; Wu, M.C.; Wei, L.; Zhao, T.S. Highly active, bi-functional and metal-free B4C-nanoparticle-modified graphite felt electrodes for vanadium redox flow batteries. J. Power Sources 2017, 365, 34-42. [CrossRef] 
18. Zhang, J.; Jiang, G.; Xu, P.; Kashkooli, A.G.; Mousavi, M.; Yu, A.; Chen, Z. An all-aqueous redox flow battery with unprecedented energy density. Energy Environ. 2018, 11, 2010-2015. [CrossRef]

19. Kim, S.; Choi, J.; Choi, C.; Heo, J.; Kim, D.W.; Lee, J.Y.; Hong, Y.T.; Jung, H.T.; Kim, H.T. Pore-Size-Tuned Graphene Oxide Frameworks as Ion-Selective and Protective Layers on Hydrocarbon Membranes for Vanadium Redox-Flow Batteries. Nano Lett. 2018, 18, 3962-3968. [CrossRef]

20. Zhu, H.Q.; Zhang, Y.M.; Yue, L.; Li, W.S.; Li, G.L.; Shu, D.; Chen, H.Y. Graphite-carbon nanotube composite electrodes for all vanadium redox flow battery. J. Power Sources 2008, 184, 637-640. [CrossRef]

21. Saha, A.; Basiruddin, S.K.; Ray, S.C.; Roy, S.S.; Jana, N.R. Functionalized graphene and graphene oxide solution via polyacrylate coating. Nanoscale 2010, 2, 2777-2782. [CrossRef] [PubMed]

22. Pezeshki, A.M.; Clement, J.T.; Veith, G.M.; Zawodzinski, T.A.; Mench, M.M. High performance electrodes in vanadium redox flow batteries through oxygen-enriched thermal activation. J. Power Sources 2015, 294, 333-338. [CrossRef]

23. So, S.; Cha, M.S.; Jo, S.W.; Kim, T.H.; Lee, J.Y.; Hong, Y.T. Hydrophilic Channel Alignment of Perfluoronated Sulfonic-Acid Ionomers for Vanadium Redox Flow Batteries. ACS Appl. Mater. Interfaces 2018, 10, 19689-19696. [CrossRef] [PubMed]

24. Zeng, L.; Sun, J.; Zhao, T.S.; Ren, Y.X.; Wei, L. Balancing the specific surface area and mass diffusion property of electrospun carbon fibers to enhance the cell performance of vanadium redox flow battery. Int. J. Hydrogen Energy 2020, 45, 12565-12576. [CrossRef]

25. Di Blasi, A.; Busacca, C.; Di Blasi, O.; Briguglio, N.; Antonucci, V. Synthesis and characterization of electrospun nickel-carbon nanofibers as electrodes for vanadium redox flow battery. J. Electrochem. Soc. 2018, 165, 1478-1485. [CrossRef]

26. Maharjan, M.; Bhattarai, A.; Ulaganathan, M.; Wai, N.; Oo, M.O.; Wang, J.Y.; Lim, T.M. High surface area bio-waste based carbon as a superior electrode for vanadium redox flow battery. J. Power Sources 2017, 362, 50-56. [CrossRef]

27. Ulaganathan, M.; Jain, A.; Aravindan, V.; Jayaraman, S.; Ling, W.C.; Lim, T.M.; Srinivasan, M.P.; Yan, Q.; Madhavi, S. Bio-mass derived mesoporous carbon as superior electrode in all vanadium redox flow battery with multicouple reactions. J. Power Sources 2015, 274, 846-850. [CrossRef]

28. Wei, G.J.; Gao, Z.G.; Wei, Z.F.; Fan, X.Z.; Liu, J.G.; Yan, C.W. Coupling effect between the structure and surface characteristics of electrospun carbon nanofibres on the electrochemical activity towards the VO2p/VO2p redox couple. Phys. Chem. Chem. Phys. 2015, 17, 20368-20375. [CrossRef]

29. Zeng, L.; Zhao, T.; Wei, L. Revealing the performance enhancement of oxygenated carbonaceous materials for vanadium redox flow batteries: Functional groups or specific surface area? Adv. Sustain. Syst. 2018, 2, 1700148. [CrossRef]

30. Estevez, L.; Reed, D.; Nie, Z.; Schwarz, A.M.; Nandasiri, M.I.; Kizewski, J.P.; Wang, W.; Thomsen, E.; Liu, J.; Zhang, J.G.; et al. Tunable oxygen functional groups as electrocatalysts on graphite felt surfaces for all-vanadium flow batteries. Chemsuschem 2016, 9, 1455-1461. [CrossRef] [PubMed]

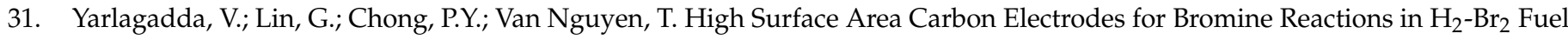
Cells. J. Electrochem. Soc. 2016, 163, 5126-5133. [CrossRef]

32. Yarlagadda, V.; Lin, G.; Chong, P.Y.; Van Nguyen, T. High Active Surface Area and Durable Multi-Wall Carbon Nanotube-Based Electrodes for the Bromine Reactions in $\mathrm{H}_{2}-\mathrm{Br}_{2}$ Fuel Cells. J. Electrochem. Soc. 2016, 163, 5134-5143. [CrossRef]

33. Jiang, H.R.; Shyy, W.; Wu, M.C.; Zhang, R.H.; Zhao, T.S. A bi-porous graphite felt electrode with enhanced surface area and catalytic activity for vanadium redox flow batteries. Appl. Energy 2019, 233-234, 105-113. [CrossRef]

34. Jiang, H.R.; Sun, J.; Wei, L.; Wu, M.C.; Shyy, W.; Zhao, T.S. A high power density and long cycle life vanadium redox flow battery. Energy Storage Mater. 2020, 24, 529-540. [CrossRef]

35. Tuinstra, F.; Koenig, J.L. Characterization of graphite fiber surfaces with Raman spectroscopy D. J. Compos. Mater. 1970, 4, 492-499. [CrossRef]

36. Nakamizo, M.; Honda, H.; Inagaki, M. Raman spectra of ground natural graphite. Carbon 1978, 16, 281-283. [CrossRef]

37. Nemanich, R.J.; Solin, S.A. First and second-order Raman seattering from finite-size crystals of graphite O. Phys. Rev. B 1979, B20, 39240.

38. Zhu, B.; Cao, W.; Wu, Y.; Cai, X.; Zhao, W. Effect of high temperature heat treatment on RMS spectrum property of carbon felt. Heat Treat. Metals 2011, 36, 8.

39. Min, J. Comparison of the Microstructure of Toray T800H and T800S Carbon Fibers. Mater. Sci. Technol. 2015, $23,45-52$. 